\title{
Ribozyme-targeting procathepsin D and its effect on invasion and growth of breast cancer cells: An implication in breast cancer therapy
}

\author{
ARUNA VASHISHTA ${ }^{1}$, SUJATA SARASWAT OHRI ${ }^{1}$, MARY PROCTOR $^{2}$, \\ MARTIN FUSEK $^{3}$ and VACLAV VETVICKA ${ }^{1}$ \\ ${ }^{1}$ Department of Pathology, University of Louisville, Louisville, KY; ${ }^{2}$ Research Resource Center, \\ University of Louisville and VA Medical Center, Louisville, KY, USA; ${ }^{3}$ Institute of Organic \\ Chemistry and Biochemistry, Czech Academy of Science, Prague, Czech Republic
}

Received November 20, 2006; Accepted January 17, 2007

\begin{abstract}
Procathepsin D (pCD), a zymogen of lysosomal aspartic peptidase cathepsin $\mathrm{D}$, overexpression is correlated with highly invasive malignancies, including breast cancer. Recently, different studies have shown the role of secreted pCD as mitogen acting both in an autocrine and a paracrine manner. The aim of the present study is to examine the antitumor effects elicited by a decrease in the protein level of pCD by ribozyme and to explore the therapeutic potential of this specific targeting. Using the mFold program, we designed seven anti-pCD ribozymes and checked the accessibility to target pCD mRNA by RNase $\mathrm{H}$ cleavage experiment in a cell-free system. The sequences of the 4 most effective ribozymes were cloned and stably transfected in a highly metastatic human breast cancer cell line, MDA-MB-231, to knock down the expression of pCD. Downregulation of $\mathrm{pCD}$ due to ribozyme expression was observed by Western blotting and real-time RT-PCR. Stably transfected cells with antipCD ribozymes exhibited a significant lowering of in vitro invasion $(\mathrm{p}<0.001)$ and reduction in lung colonization potential in nude mice when compared to control ribozyme transfected cells. We also found that downregulation of $\mathrm{pCD}$ by ribozyme promotes apoptosis of MDA-MB-231 cells on serum deprivation. These results suggest that we have generated a biologically functional ribozyme against $\mathrm{pCD}$ with possible therapeutic implications in breast cancer cells.
\end{abstract}

\section{Introduction}

Breast cancer is one of the most lethal malignancies among women in the Western world. Proteins that are overexpressed

Correspondence to: Dr Vaclav Vetvicka, Department of Pathology, University of Louisville, 511 S. Floyd Street, MDR Bldg., Louisville, KY 40292, USA

E-mail: vaclav.vetvicka@louisville.edu

Key words: breast cancer, invasion, procathepsin D, ribozyme, tumor growth and secreted in a disease-specific manner provide possible targets for therapeutics, early detection and monitoring of disease during and after treatment.

Procathepsin D (pCD) is a proform of lysosomal aspartic peptidase cathepsin D (CD) that is overexpressed (2- to 50fold) and secreted by breast cancer tissues and cell lines (1-3). In normal cells, CD is translated as preprocathepsin D in rough endoplasmic reticulum and is translocated to golgi apparatus as pCD $(52 \mathrm{kDa})$ after removal of signal peptide. The pCD is then sorted to lysosomes, where it is activated at low $\mathrm{pH}$ to a single-chain proteolytically active form by removal of activation peptide (AP) and further cleaved into a two-chain mature form of 33 and $14 \mathrm{kDa}$ respectively (4). The mature CD participates in intracellular protein catabolism, hormone and antigen processing, and apoptotic pathway $(5,6)$. However, the proform, pCD, is correlated with enhanced proliferation and neoplastic transformation $(7,8)$. Clinical studies using immunoassays have reported that $\mathrm{pCD} / \mathrm{CD}$ is a marker of poor prognosis for breast cancer and is associated with a high risk of metastasis (9-13). Various studies performed on the cell culture as well as on a mouse model have shown that the transfection of pCD in cancer cell lines influences the growth of cancer cells and that the rate of growth was related to the level of pCD expression $(14,15)$. Therefore, targeting pCD by genetic means could help to better understand its role in tumor growth. For this purpose, we used ribozyme directed against pCD as a tool.

Hammerhead ribozymes are small catalytic RNAs with the potential to ablate gene expression in a highly sequencespecific manner and are therefore useful in analyzing gene function and as a therapeutic approach against various human diseases $(16,17)$. Ribozymes possess the unique characteristic of cleaving RNA without the additional help of an enzyme (16). Ribozyme has the antisense effect as well as catalytic activity, both of which contribute to the activity of ribozyme (18). Multiple turnovers, i.e. binding and cleaving of the substrate, dissociation and binding to a new target molecule, provide an additional advantage to ribozyme. We used a hammerhead ribozyme approach to target and suppress pCD gene expression in vitro and in vivo and further determine pCD's role in cancer invasion and metastasis. 
In the present study, we first tested all the designed ribozymes under physiological conditions in a cell-free system followed by cloning of the effective ribozymes in expression vector. The constructs were stably transfected in breast cancer cell line MDA-MB-231 and downregulation of pCD expression was monitored both at mRNA and protein levels. Attenuation of pCD expression by ribozyme resulted in a great reduction of cell invasion in vitro and lung colonization in vivo in nude mice.

\section{Materials and methods}

Cell lines and cell culture. Breast cancer cell line MDAMB-231 was obtained from Dr R. Ceriani of the John Muir Cancer and Aging Research Institute, Walnut Creek, CA. The cell line was cultured in RPMI-1640 (Sigma Chemical Co., St. Louis, MO) with $10 \%$ fetal calf serum (FCS; Hyclone Lab., Logan, UT), $100 \mathrm{U} / \mathrm{ml}$ penicillin (Sigma) and $100 \mu \mathrm{g} / \mathrm{ml}$ streptomycin (Sigma) at $37^{\circ} \mathrm{C}$ in $5 \% \mathrm{CO}_{2}$.

Design of anti-pCD ribozymes and analysis of accessible site using RNase H mapping. The procedure has been previously reported (15). Briefly, the secondary structure of human pCD was generated using RNA mFOLD program version 3.1 (19). The suitable GUC sites within the pCD mRNA were identified. The sense and antisense oligodeoxyribonucleotide (ODN) corresponding to ribozyme target sequences identified by mFOLD program were designed. MDA-MB-231 cells $\left(3 \times 10^{7}\right)$ were pelleted and washed twice in phosphate-buffered saline (PBS). The pellet was resuspended in hypotonic buffer (7 mM Tris- $\mathrm{HCl}$, pH 7.5, $7 \mathrm{mM} \mathrm{KCl}, 1 \mathrm{mM} \mathrm{MgCl}_{2}, 1 \mathrm{mM}$ B-mercaptoethanol), incubated for $10 \mathrm{~min}$ on ice, sonicated with pulse of $10 \mathrm{sec}$ followed by addition of $1 / 10$ of the final volume of neutralizing buffer $(21 \mathrm{mM}$ Tris- $\mathrm{HCl}, \mathrm{pH} 7.5$, $116 \mathrm{mM} \mathrm{KCl}, 3.6 \mathrm{mM} \mathrm{MgCl}$, $6 \mathrm{mM} \mathrm{B-mercaptoethanol).}$ The homogenate was centrifuged at 13,000 rpm for $15 \mathrm{~min}$ at $4^{\circ} \mathrm{C}$. The $\mathrm{RNaseH}$-mediated cleavage experiment was carried out in a total volume of $30 \mu \mathrm{l}$, containing $20 \mu \mathrm{l}$ of cell extract, $1 \mathrm{mM}$ DTT, $40 \mathrm{U}$ of RNase inhibitor (Ambion Inc., Austin, TX) and $50 \mathrm{nM}$ of the various antisense ODNs and sense ODN (control). The mixture was incubated for $15 \mathrm{~min}$ at $37^{\circ} \mathrm{C}$ followed by digestion with $10 \mathrm{U}$ of DNase I (Ambion Inc.) for $45 \mathrm{~min}$ at $37^{\circ} \mathrm{C}$ and then subjected to phenol extraction and ethanol precipitation. Reverse transcription (RT) was performed using two-step RT-PCR kit (Invitrogen, Carlsbad, CA) in $20 \mu \mathrm{l}$ using $50 \mathrm{ng}$ of random hexamer primer and $10 \mathrm{U}$ of Moloney murine leukemia virus reverse transcriptase. An aliquot of $18 \mu \mathrm{l}$ of each RT reaction was PCR-amplified using pCD primers: (5'-CCAGTACTACG GGGAGATTG-3' and 5'-CCATAGTGTGGATGTCAAA CGA-3') and $2 \mu \mathrm{l}$ using the $\beta$-actin primers (5'-TGCTATC CAGGCTGTGCTAT-3' and 5'-TTCCAGTTTTTAAATC CTGAGTC-3') for 25 cycles. PCR was carried out in $50 \mu 1$ with $1.5 \mathrm{U}$ of Taq DNA polymerase at $94^{\circ} \mathrm{C}$ for $30 \mathrm{sec}, 62^{\circ} \mathrm{C}$ for $45 \mathrm{sec}, 72^{\circ} \mathrm{C}$ for $90 \mathrm{sec}$ with final extension at $72^{\circ} \mathrm{C}$ for $7 \mathrm{~min}$. The PCR products were resolved on $1.5 \%$ agarose gel and visualized after staining with ethidium bromide.

Construction of ribozyme expression vector. The ribozymes designated as control RZ, RZ385, RZ644, RZ763 and RZ1254 were PCR amplified using the overlapping oligos which have a SalI site at the $5^{\prime}$ end and a HindIII site at the $3^{\prime}$ end. The PCR products were digested with SalI and HindIII and cloned in SalI and HindIII digested pHßApr-1-neo vector to produce a plasmid where the expression of ribozyme was driven by $ß$-actin promoter. The direction and sequence were verified using plasmid-specific primers: 5'-CCTCCGACCAGTGT TTGC-3' and 5'-GTCTGGATCCCTCGAAGC-3'.

Transfection. The MDA-MB-231 human breast cancer cell line was cultured in normal growth medium overnight to obtain 70-80\% confluency. The following day, the cells were transfected with $1.5 \mu \mathrm{g}$ of plasmid DNA mixed with $2.5 \mu \mathrm{l}$ of Lipofectamine-2000 reagent (Invitrogen) in Optimem-I media (Invitrogen). After $5 \mathrm{~h}$, the transfection medium was replaced with normal medium and the cells were grown for an additional $24 \mathrm{~h}$. For generation of stable clones, the cells were incubated in the presence of Geneticin (G418-sulfate; Invitrogen) over a period of 3 weeks. Finally, clonal expansion was performed in a 96-well plate and the positive stable clones were checked on a Western blot.

Western blot analysis. Control and stably transfected MDAMB-231 cells $\left(2 \times 10^{5}\right.$ cells $\left./ \mathrm{ml}\right)$ were seeded in normal growth medium followed by replacement with medium containing $0.1 \%$ FCS and allowed to grow for another $48 \mathrm{~h}$. Supernatants were collected, concentrated (10X) using centricon (Pall Life Sciences, Ann Arbor, MI) and $10 \mu \mathrm{g}$ protein (estimated by BCA protein Assay Kit; Pierce, Rockford, IL) was resuspended in Laemmli buffer (BioRad, Hercules, CA). For lysates, the control and transfected cells were trypsinized, and washed twice with cold PBS. The cell pellet was then dissolved in cold lysis buffer $(10 \mathrm{mM}$ Tris, $5 \mathrm{mM}$ EDTA, 150 mM NaCl, 1\% Triton-X 100, pH 7.4 containing protease inhibitors cocktail; Sigma). Lysis was performed on ice for $30 \mathrm{~min}$. Protein lysate was then cleared by centrifugation and $20 \mu \mathrm{g}$ of each protein sample was resuspended in Laemmli buffer. Electrophoresis and immunoblotting was performed as described (20). The monoclonal antibody anti-AP (21), anti-CD antibody (Calbiochem, San Diego, CA) and the polyclonal anti-ß-actin antibody (Ambion Inc.) were used.

RT-PCR analysis. Total cellular RNA was extracted from the control and transfected MDA-MB-231 cells using TRIzol reagent (Invitrogen) according to the manufacturer's instructions and extensively treated with RNase-free DNase. Total cellular RNA $(1 \mu \mathrm{g})$ of control and each transfectant were reverse transcribed in a volume of $20 \mu 1$ using the Superscript ${ }^{\mathrm{TM}}$ first-strand synthesis system (Invitrogen). An aliquot of $2 \mu 1$ of RT product was PCR amplified using the plasmid-specific primers (described above) to check for ribozyme expression and also with pCD primers and $ß$-actin primers (internal control) to check the pCD expression and the equal amount of RNA respectively. PCR amplification for $\mathrm{pCD}$ and actin was performed for 25 cycles as described above and for RZ expression initial denaturation was performed at $94^{\circ} \mathrm{C}$ for 2 min followed by 30 cycles of $94^{\circ} \mathrm{C}$ for $30 \mathrm{sec}, 55^{\circ} \mathrm{C}$ for $30 \mathrm{sec}$ and $72^{\circ} \mathrm{C}$ for $30 \mathrm{sec}$ and final extension at $72^{\circ} \mathrm{C}$ for $7 \mathrm{~min}$. The PCR products were separated on $1.5 \%$ agarose gel and visualized by ethidium bromide staining. 
Real-time RT-PCR. Messenger RNA was isolated from transfected MDA-MB-231 cells and control cells using the TRIzol reagent (Invitrogen). The cDNA was synthesized using $250 \mathrm{ng}$ of total RNA and TaqMan reverse transcription reagents (Applied Biosystems, Foster City, CA) in $25 \mu 1 \mathrm{RT}$ reaction. Real-time PCR reaction was then carried out in a total of $20 \mu \mathrm{l}$ of reaction mixture using $2 \mu \mathrm{l}$ cDNA per reaction, $5 \mu \mathrm{M}$ of each cat D primer (forward: 5'-GGACATCGCTTG CTGGAT-3' and reverse: 5'-CTTGGCTGCGATGAAGGT-3') or ß-actin primer (forward: 5'-CACTGGCATCGTGATGGA-3' and 5'-GGCCATCTCTTGCTCGAA-3') and $10 \mu 1$ of $2 \mathrm{X}$ SYBR-Green PCR Core Reagents on ABI PRISM Sequence Detection System 7300 (Applied Biosystems). The PCR program was initiated by $10 \mathrm{~min}$ at $95^{\circ} \mathrm{C}$ before 40 thermal cycles, each for $15 \mathrm{sec}$ at $95^{\circ} \mathrm{C}$ and $1 \mathrm{~min}$ at $60^{\circ} \mathrm{C}$. At the end of the PCR cycle, a dissociation curve was generated to ensure the amplification of a single product and the threshold cycle time (Ct values) for each gene was determined. Relative mRNA levels were calculated based on the $\mathrm{Ct}$ values normalized to the housekeeping gene, $\beta$-actin.

In vitro invasion analysis and proliferation assay. A commercial kit by Chemicon International (Temecula, CA) was used to evaluate the invasion across Matrigel layers according to the manufacturer's instructions. Briefly, $3 \times 10^{5}$ cells were added to each well and after $24 \mathrm{~h}$, the cells that had migrated through the matrix and adhered to other side of the insert were fixed and stained with $0.5 \%(\mathrm{w} / \mathrm{v})$ crystal violet. Cells that had invaded and stained with crystal violet were extracted with $10 \%$ (v/v) acetic acid. An aliquot of stained cells was transferred to a 96-well plate and absorbance was obtained at $560 \mathrm{~nm}$ using a multiplate reader.

For cell growth assay, control and stably transfected cells were plated into a 96-well plate at $5 \times 10^{4}$ cells/ml $(150 \mu 1 /$ well). Cells were evaluated for proliferation on the day of plating and day 1,2, 3 and 4 after plating using a Biotrak Cell proliferation ELISA system (Amersham Pharmacia Biotech, Piscataway, NJ) according to the manufacturer's instructions. The growth of cells is shown here as absorbance.

In vivo studies in nude mice. Four- to six-week-old athymic nude mice (Jackson lab, Bar Harbor, ME) were injected i.v. with $0.2 \mathrm{ml}$ of a cell suspension containing $4 \times 10^{6}$ MDAMB-231 cells or cells stably transfected with RZ1254 or with control RZ construct. Six weeks after cell injection, mice were euthanized by inhalation of $\mathrm{CO}_{2}$. A complete necropsy was performed on all mice and the heart, lungs, kidney, liver, spleen and parts of the intestinal tract were removed and fixed in $10 \%$ buffered formalin. Fixed tissues were trimmed and paraffin-embedded for processing. The blocks were cut into $4-\mu \mathrm{m}$ sections and stained with hematoxylin and eosin for histopathology examination. A minimum of six mice per group was used.

MTT assay. Control and stably transfected MDA-MB-231 cells $\left(7 \times 10^{3}\right)$ were plated onto each well $(100 \mu 1 /$ well $)$ of 96-well culture plates in $2 \%$ FCS for the specified time. MTT (Sigma) solution ( $10 \mu \mathrm{l}$ from $5 \mathrm{mg} / \mathrm{ml}$ stock) was then added to each well, and the plates were further incubated at $37^{\circ} \mathrm{C}$ for $4 \mathrm{~h}$ in a humidified incubator with $5 \% \mathrm{CO}_{2}$.
Table I. Sequences of antisense and control sense ODNs corresponding to ribozyme target sequences identified by mFOLD program.

\begin{tabular}{ll}
\hline Antisense RZ94 & 5'-CGGATGGACGTGAACTTG-3' \\
Antisense RZ385 & 5'-GTGCTGGACTTGTCGCTGT-3' \\
Antisense RZ644 & 5'-GTCGAAGACGGGCAGCAC-3' \\
Antisense RZ763 & 5'-TTGTAATACTTGGAGTCTG-3' \\
Antisense RZ774 & 5'-ACAGAGAACCCTTGTAATAC-3' \\
Antisense RZ1127 & 5'-TGGCGGGATGTCCATGC-3' \\
Antisense RZ1254 & 5'-CGCGCGGACGCCUUGGGAA-3' \\
Sense control & 5'-ACAGCGACAAGTCCAGCAC-3' \\
\hline
\end{tabular}

The medium was then aspirated to ease the formation of the formazan product, which was then solubilized with the addition of $100 \mu 1$ of acidic isopropanol. The optical density was measured at $570 \mathrm{~nm}$ with reference wavelength of $630 \mathrm{~nm}$ using a SLT ELISA reader (Tecan, Research Triangle Park, NC). Similar experiments were repeated in triplicates.

Cell death detection ELISA. Apoptosis was studied with the detection and quantification of cytoplasmic histoneassociated DNA fragments (mono- and oligo-nucleasomes) by photometric enzyme immunoassay (Cell Death Detection ELISA, Roche Diagnostics, Mannheim, Germany). The control cells and stably transfected cells were seeded in 12-well plates and after $24 \mathrm{~h}$ the cells were deprived of serum for $48 \mathrm{~h}$. The cells were lysed and centrifuged followed by analysis of cytoplasmic histone-associated DNA fragments according to the manufacturer's instructions. Results were from three different experiments performed in triplicate.

Statistical analysis. All data were expressed as mean \pm standard deviation (SD). Statistical comparisons between two groups or among groups were determined using t-test or one-way ANOVA. A p-value of $<0.05$ was considered statistically significant.

\section{Results}

Designing of ribozymes and demonstration of accessibility of ribozyme to target $p C D m R N A$ in cell-free system. Using mFOLD program version 3.1, seven hammerhead ribozymes against pCD mRNA 'GUC motifs' were designed (15). Ribozymes were numbered according to the position of the cleavage site in pCD mRNA sequence. To evaluate the accessibility of different sites in intracellular environment, we designed antisense and control sense ODNs corresponding to ribozyme target sequences as shown in Table I. The antisense ODNs (asODN) were allowed to bind to native pCD mRNA in cell extracts followed by cleavage with endogenous RNase $\mathrm{H}$ and quantification by RT-PCR of the remaining uncleaved mRNA. The asODNs corresponding to RZ385, RZ644, RZ763 and RZ1254 were most effective in cell extracts, reducing the pCD mRNA levels to almost negligible (Fig. 1). As an efficiency control, sense ODN was used. These results indicate that the 'GUC motif' at positions 385, 644, 763 and 1254 


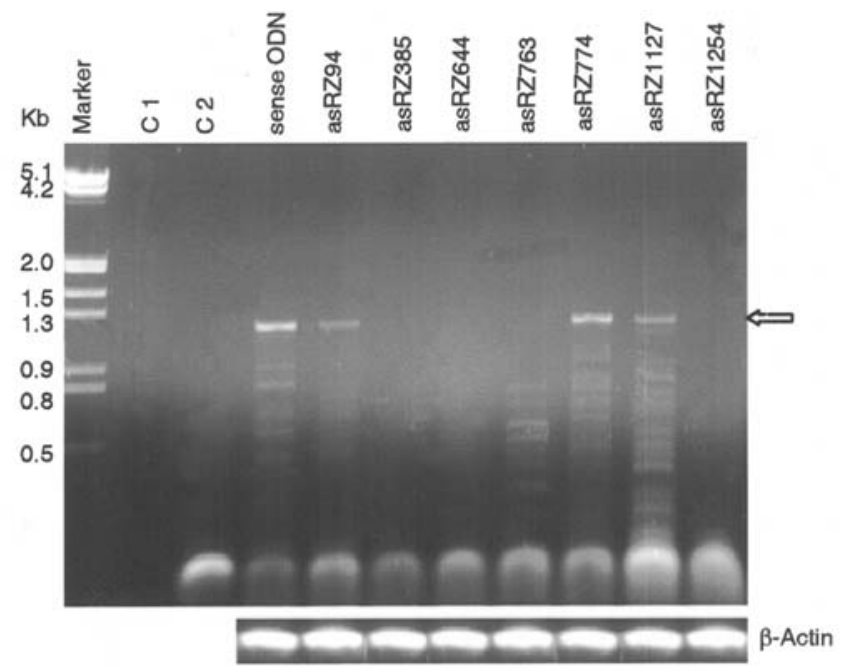

Figure 1. RNase H-mediated cleavage of endogenous pCD mRNA in cell extracts using anti-pCD ODNs. MDA-MB-231 cell extract was treated with the sense ODN as well as various antisense ODNs $(50 \mathrm{nM})$ corresponding to ribozyme target sites. The cleaved RNA was reverse transcribed using hexamer primer. Different aliquots of RT products were amplified using pCD primers and $\beta$-actin primers as internal control. A band of $\sim 1.2 \mathrm{~kb}$ pCD mRNA was obtained with sense ODN and reduction of pCD mRNA with various antisense ODNs was compared to control sense ODN in the ethidium bromide gel.

in the pCD mRNA is accessible to ribozyme in a cell-free system.

Intracellular model system for studying the specificity and efficacy of $p C D$ ribozyme. The catalytic activity of the four promising ribozymes designated as RZ385, RZ644, RZ763 and RZ1254 was then tested in cells. These hammerhead ribozymes were cloned into the pHßApr-1-neo expression vector where a ribozyme expression is under the control of $B$-actin promoter. Catalytically inactive mutant ribozyme was designed by changing the G-A in the catalytic domain of ribozyme that resulted in a loss of catalytic activity. The human breast cancer cell line MDA-MB-231 was transfected with empty vector, vector with control, and effective ribozymes. Stable transfectants were selected for each and analyzed by Western blotting and RT-PCR. As shown in Fig. 2A, expression of pCD in MDA-MB-231 cells transfected with empty vector and control RZ was not altered while the RZ385, RZ644, RZ763 and RZ1254 led to a drastic reduction of pCD protein amount in conditioned media (Fig. 2A, upper panel). The level of $\mathrm{CD}$ protein in cell lysates was also affected by transfection of these effective ribozymes (Fig. 2A, middle panel). Equal loading of protein is shown by detection of actin on the identical blot (Fig. 2A, lower panel).

To ensure that downregulation of $\mathrm{pCD}$ was due to ribozyme activation, RT-PCR analysis was performed using pCD primers (Fig. 2B, upper panel), RZ primers (Fig. 2B, middle panel) and actin primers ( Fig. 2B, lower panel) as control. As shown in Fig. 2B, the anti-pCD ribozymes were capable of downregulating pCD mRNA expression significantly in MDA-MB-231 cells, while no change was observed in control $\mathrm{RZ}$ and empty vector transfected cells. The reduction of $\mathrm{pCD}$
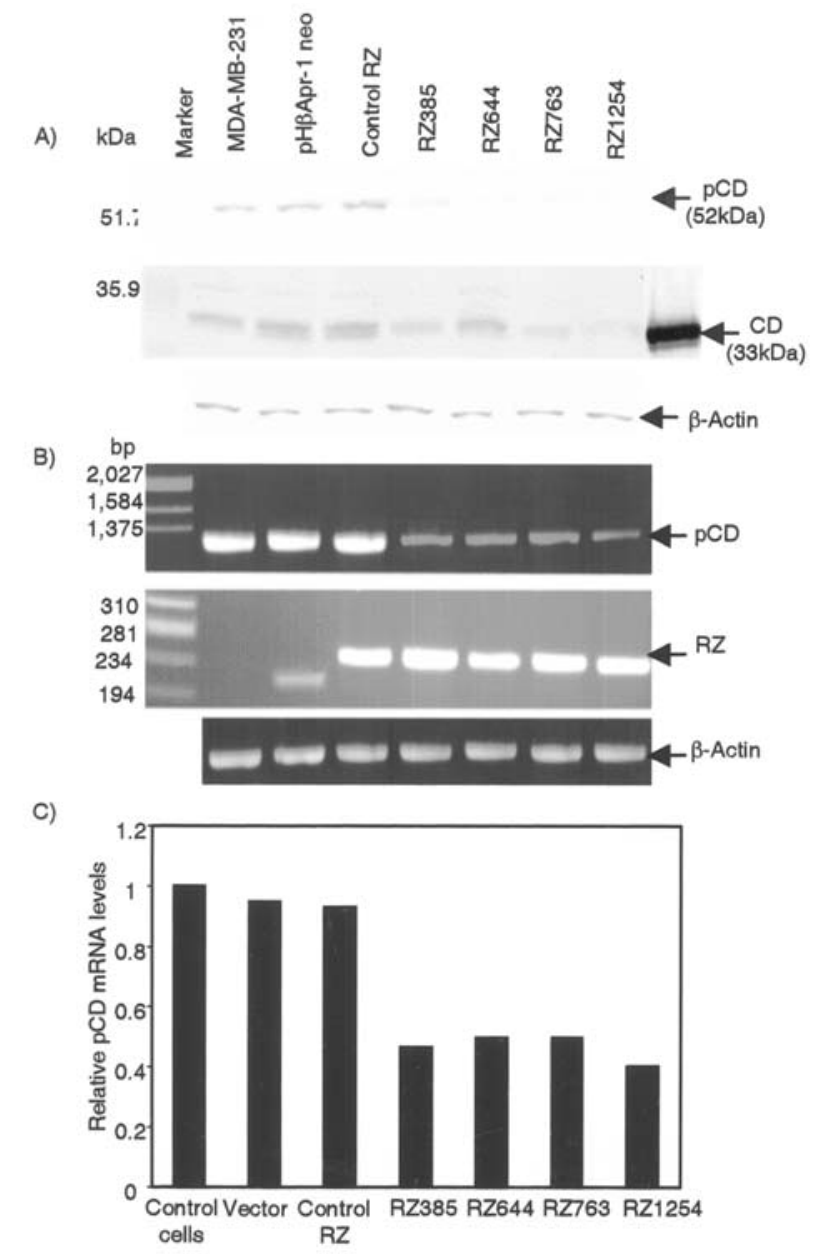

Figure 2. Ribozyme-mediated downregulation of $\mathrm{pCD}$ at both protein (A) and mRNA (B and C) level in MDA-MB-231 cells. (A) MDA-MB-231 cells as well as stably transfected with pHßApr-1-neo, vector with control RZ sequence and four effective ribozymes were checked for the secreted $\mathrm{pCD}$ and intracellular cathepsin D level. Equal amounts of total protein were loaded on SDS-PAGE and subsequently analyzed by Western blotting. Expression of pCD protein in cell supernatant was detected using anti-AP antibody (upper panel), CD expression was detected in cell lysates using anti-CD antibody, where purified CD was used as control in the last lane (middle panel) and equal protein was confirmed by immunoblotting with anti-ß-actin antibody (lower panel). (B) To check the expression of pCDmRNA and transfected ribozymes, total RNA was extracted from nontransfected as well as transfected MDA-MB-231 cells. RT-PCR analysis was performed using pCD primers (upper panel, 25 cycles), plasmidspecific primers (middle panel, 30 cycles) or $\beta$-actin primers (lower panel, 25 cycles). (C) The level of reduction of pCD-mRNA was assessed by real-time RT-PCR, and the results are expressed as relative pCD mRNA level compared to the control cells based on the $\mathrm{Ct}$ values normalized to the housekeeping gene, $\beta$-actin.

mRNA (50-60\%) was also confirmed by real-time RT-PCR (Fig. 2C). Expression of ribozymes was seen in RT-PCR demonstrating that the transfection of ribozyme vectors resulted in ribozyme expression. These results demonstrate the efficacy, efficiency, and specificity of pCD ribozymes in cells.

Further, the expression of active ribozymes from $\mathrm{pH} \beta \mathrm{Apr}$ 1-neo vector was detected in MDA-MB-231 cells for multiple passages following transfection. The expression of ribozymes in cells was seen further than passage 20 (data not shown). This demonstrates that the construct is stable in the cells. 


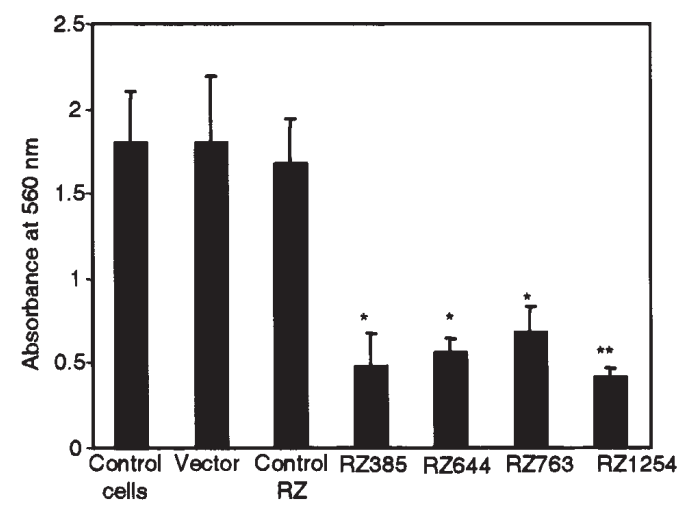

Figure 3. Effect of anti-pCD ribozymes on cell invasion. In vitro invasiveness through Matrigel membrane of MDA-MB-231 cells, stably transfected control ribozyme and active ribozymes cells was measured. The cells $\left(3 \times 10^{5}\right)$ were incubated on the top of Matrigel-coated filters and the extent of cell invasion was measured after staining the invasive cells by colorimetric reading at $\mathrm{OD}_{560 \mathrm{~nm}}$. The experiment was repeated thrice and the data represent the mean \pm SD of three independent experiments. ${ }^{*} \mathrm{p}<0.05 ;{ }^{* *} \mathrm{p}<0.001$ vs. mean of control (ANOVA analysis).

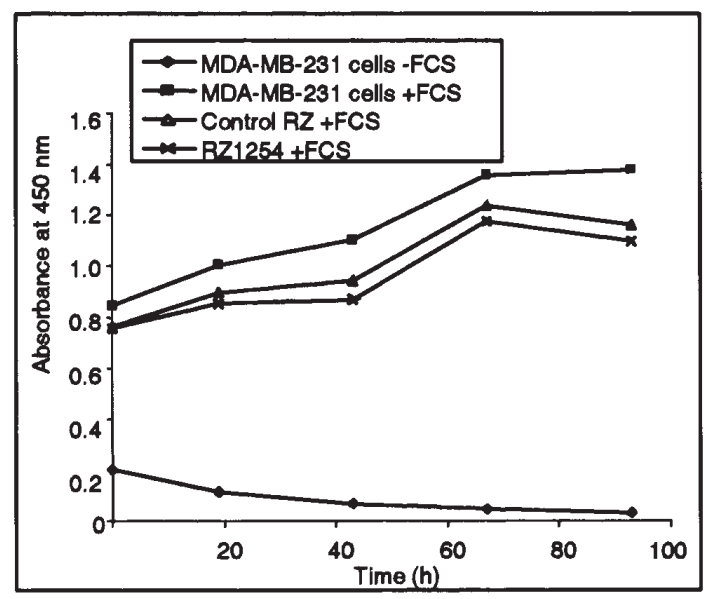

Figure 4. Effect on proliferation of MDA-MB-231 cells by downregulation of pCD expression. MDA-MB-231 cells as well as cells stably transfected with control RZ and RZ1254 were seeded in 96-well plates at a density of $5 \times 10^{4}$ cells $/ \mathrm{ml}(150 \mu 1 /$ well $)$ in the presence of $10 \%$ FCS and incubated for time intervals of $0,19,43,67$ and $93 \mathrm{~h}$ followed by evaluation of proliferation using a Biotrak ELISA system. The figure shows a representative cell growth analysis of three similar independent experiments.

Downregulation of $p C D$ in cell lines expressing and secreting $p C D$ affects the in vitro invasiveness of breast cancer cells. The correlation between the pCD secretion and invasive potential of different cancer cell lines has been established $(15,20,22)$. Preliminary study using one of the designed ribozymes has shown reduction in invasion through Matrigel in the ZR-75-1 breast cancer cell line (15). Therefore, the effect of downregulation of $\mathrm{pCD}$ expression by anti-pCD ribozymes on the invasive potential of MDA-MB-231 cells was evaluated using the Matrigel invasion assay. All the active ribozyme transfected cells showed reduction in invasion through Matrigel membrane and the most significant effect was seen in cells transfected with RZ1254 (Fig. 3). In contrast, the empty vector and control RZ transfected cells showed similar invasion as wild-type MDA-MB-231 cells.
Table II. Inhibition of experimental metastasis by knockdown of $\mathrm{pCD}$.

\begin{tabular}{lcc}
\hline Cell line & $\begin{array}{c}\text { Incidence } \\
\text { (macroscopic } \\
\text { lung colonies) } \\
4 \times 10^{6} \text { cells }\end{array}$ & $\begin{array}{c}\text { Survival } \\
1 \times 10^{7} \text { cells }\end{array}$ \\
\hline MDA-MB-231 & $10 / 10$ & $0 / 7$ \\
$\begin{array}{l}\text { MDA-MB-231 } \\
\text { with control RZ }\end{array}$ & $9 / 9$ & $0 / 5$ \\
$\begin{array}{l}\text { MDA-MB-231 } \\
\text { with RZ1254 }\end{array}$ & $2 / 10$ & $5 / 6$ \\
\hline
\end{tabular}

Nude mice were injected with a specified number of control or antipCD ribozyme transfected MDA-MB-231 cells via the tail vein. Mice were euthanized after 6 weeks and metastatic foci were checked on the lung surface macroscopically. Number of mice with metastasis/ number of mice injected.

The cell growth of control RZ and RZ1254 transfected MDA-MB-231 cells was then accessed. In proliferation assay, we observed only $5 \%$ reduction between the control RZ and RZ1254 transfected cells over a period of $96 \mathrm{~h}$ in the presence of $10 \%$ FCS (Fig. 4).

Anti-tumor activity of pCD-ribozyme in breast cancer cells. For in vivo analysis, $4 \times 10^{6} \mathrm{MDA}-\mathrm{MB}-231$ cells or those stably transfected with control RZ or RZ1254 were injected intravenously through the tail veins of athymic nude mice. After 6 weeks, the mice were euthanized and lung tissue was examined. All the mice injected with wild-type or transfected with control RZ cells showed macroscopic lung colonization while only 2 of the 10 recipients of RZ1254 transfected cells developed macroscopic lung metastases (Table II). Additionally, microscopic examinations of tissue sections revealed infiltration of tumor cells and almost complete replacement of normal lung parenchyma by tumor cells in the case of MDA-MB-231 cells and cells transfected with control RZ while the cells transfected with RZ1254 showed no infiltration of tumor cells. Instead, they were nested adjacent to bronchioles and capillaries (Fig. 5). Further, inflammation and necrosis associated with the periphery of tumor masses was observed in the case of MDA-MB-231 cells and cells transfected with control RZ whereas no necrosis and only minimal inflammation was observed with cells transfected with RZ1254. In a separate set of experiments, $1 \times 10^{7}$ cells were injected into mice through the tail vein and checked for survival after six weeks. None of the recipients of the MDA-MB-231 cells and cells transfected with control RZ survived while $80 \%$ of the RZ1254 transfected cell recipients survived.

Induction of apoptosis in anti-pCD ribozyme transfected $M D A-M B-231$ cells on serum deprivation. Interestingly, the growth inhibitory effects of ribozyme expression appeared to 

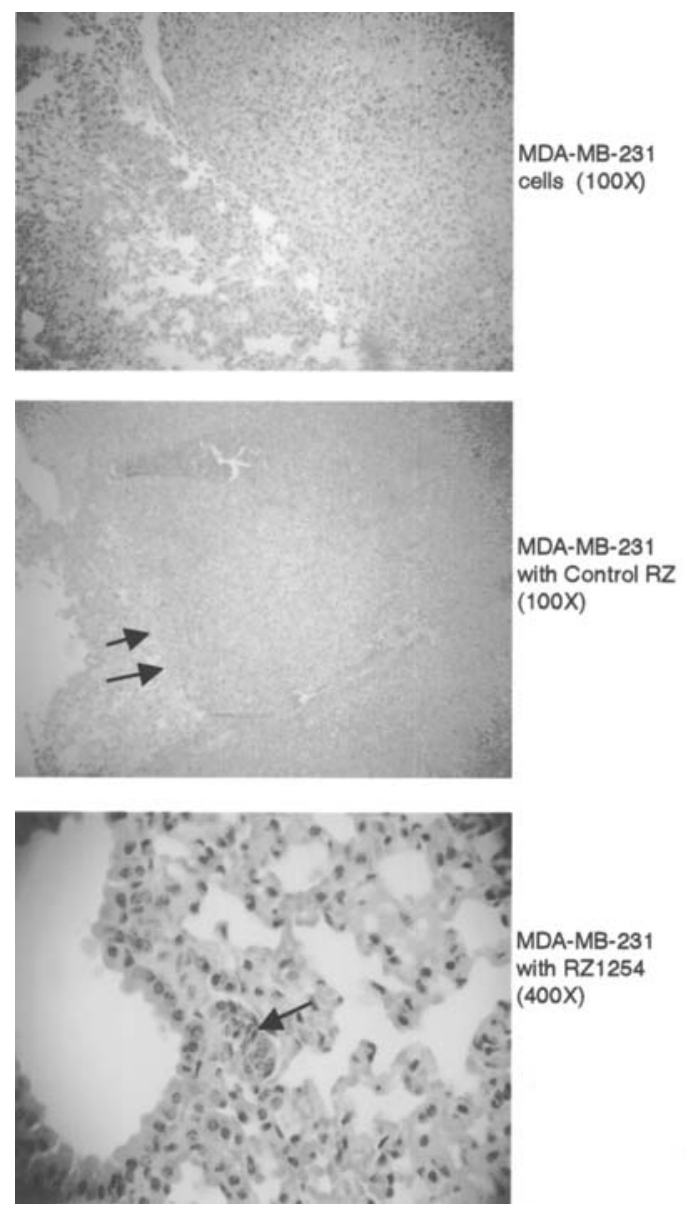

Figure 5. Effect of anti-pCD ribozyme on lung colonization of MDA-MB-231 cells in vivo. Histological analysis of hematoxylin and eosin-stained sections of lung tissue from nude mice injected with MDA-MB-231 cells, or cells stably transfected with control RZ and RZ1254. One representative slide of each is shown. As seen in the slide of wild-type cells and cells transfected with control RZ, the lung parenchyma were totally replaced by tumor cells and arrows mark the region of inflammation and tissue necrosis. In the case of cells transfected with RZ1254 tumor cells nested adjacent to bronchioles and capillaries (arrow mark) and no necrosis was apparent. Original magnification is specified.

be more profound in vivo than in vitro. To determine whether attenuation of pCD could promote death of tumor cells on stress, MTT assay and cell death detection ELISA were performed upon serum starvation. The control cells, control RZ and RZ1254 transfected cells were seeded in 2\% FCS and checked for cell viability by MTT assay every $24 \mathrm{~h}$. As shown in Fig. 6A, the RZ1254 transfected cells showed loss of cell viability after $48 \mathrm{~h}$ in contrast to control cells and control RZ. To clarify that the reduction in cell proliferation was a result of induced apoptosis, control cells, control RZ and RZ1254 cells were deprived of serum for $48 \mathrm{~h}$ and analyzed by cell death detection ELISA. The data showed that MDA-MB-231 cells transfected with RZ1254 underwent $36 \%$ apoptosis after serum starvation compared to control cells (Fig. 6B).

\section{Discussion}

Elevated levels of pCD have been seen in many types of malignancies as reviewed by Leto et al (7). Different studies

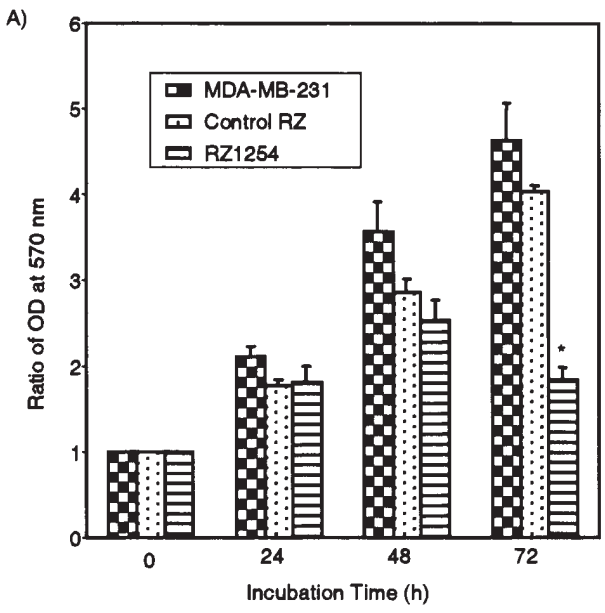

B)

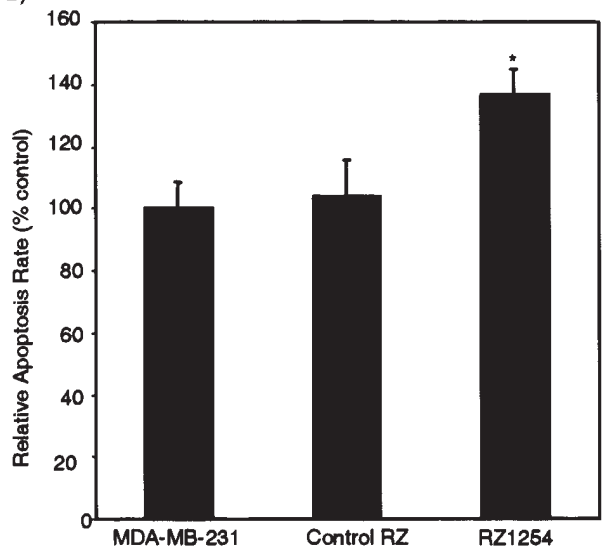

Figure 6. Inhibitory effect on cell viability in low serum condition and apoptosis induction after serum deprivation by downregulation of pCD in MDA-MB-231 cells. (A) Cell viability of the control cell and cells transfected with control RZ and RZ1254 was estimated by MTT assay. All values of OD are relative to the OD at $0 \mathrm{~h}$. (B) Control and stably transfected cells were deprived of serum for $48 \mathrm{~h}$ and apoptosis was studied by cell death ELISA kit. RZ1254 showed a loss of cell viability and increase in apoptosis after $48 \mathrm{~h}$ in contrast to control cells and cells transfected with control RZ. The data are expressed as mean \pm SD from three independent experiments. ${ }^{*} \mathrm{p}<0.05$.

have shown that $\mathrm{pCD}$ affects proliferation of cancer cells in vitro and in vivo and it plays an essential role in tumor angiogenesis and apoptosis (23). In fact, a positive correlation has been established between the proportion of pCD secreted by human breast cancer cell lines and their invasive potential (22). Moreover, studies performed in our laboratory have shown that pCD acts as a mitogen on both parental and neighborhood cancer cells through the interaction of its AP with an unidentified cell surface receptor $(24,25)$. Recently, we showed that the AP-treatment of ZR-75-1 cells induced the expression of genes involved in signal transduction, cell cycle regulation, tumor invasion, and metastasis (26). Another study has shown a paracrine communication between cancer and stromal cells where the pCD secreted by cancer cells stimulates fibroblast proliferation, survival, motility and invasion as well as activates the ras-MAP kinase pathway (27). Taken together, these studies suggest an important role of the pCD molecule in the biology of cancer and make it an attractive candidate as a therapeutic target.

In the present study, we used the ribozyme approach to cleave the pCD mRNA and to further study the effect of 
this depletion on invasion and growth of cancer cells. The ribozymes were designed to cleave distinct GUC-recognition sites of the pCD-mRNA using the mFOLD program. Although computer programs could predict the accessible sites on the RNA substrate, the most effective cleavage sites of the target are found by experimental approaches (28). As in living cells, RNA structure and thus accessibility depend on the intracellular environment. Common methods to determine effective cleavage sites are the RNase $\mathrm{H}$ treatment of the substrate after binding to antisense ODN predicted by the computer program (29) and in vitro cleavage assays (18). As expected, the seven anti-pCD hammerhead ribozymes showed strikingly different accessibility in the RNase $\mathrm{H}$ experiment. The RNase H reaction with asRZ385, asRZ644, asRZ763 and asRZ1254 showed that these sites are most accessible. The ribozyme transgene constructs were made by using $\beta$-actin promoter vector and succeeded in having a highly active, non-regulated activation of ribozymes. The effect of ribozymes was evaluated at mRNA and protein level. The real-time RT-PCR results revealed that anti-pCD ribozymes attenuated the mRNA by $55-60 \%$. Further analysis at protein level showed that the attenuation of secreted $\mathrm{pCD}$ was more than the intracellular CD. This could be due to the fact that the secretion of pCD is due to its overexpression and oversaturation of the 'normal' targeting mechanism(s) to lysosomes $(22,30)$. If such targeting mechanism(s) is oversaturated, the reduction of $\mathrm{pCD}$ production will initially be seen in the molecules secreted from cells and later on the intracellular level of normally targeted CD.

The effect of downregulation of $\mathrm{pCD}$ by a ribozyme transgene was further examined on in vitro invasion. The results revealed that the invasive potential of ribozyme transfected cells was significantly reduced when compared to control cells. Previously, using the pCD antisense oligonucleotide approach, Glondu et al (31) have also shown reduction in growth of antisense-transfected cells in tridimentional matrices and in vivo in nude mice but reported no effect on in vitro invasion. According to them, cathepsin $\mathrm{D}$ is more essential for tumor growth than for invasion, while our earlier study (15) and those of others (22) have shown that secreted pCD does affect the invasive potential of cells. Our result, therefore, is in line with the studies that reduction in $\mathrm{pCD}$ secretion affects the invasive potential of cells. Further the impact of pCD knockdown on cell growth was investigated. The effect on cell growth in vivo was found to be more prominent than in vitro. Therefore, the growth of control and ribozyme transfected cells was monitored in serum deprivation stress condition and the result showed that the ribozyme transfected cells lost viability after 2 days in low serum conditions. One possibility is that depletion of pCD promotes the death of tumor cells on serum starvation. The cell death assay result showed an increase in apoptosis in ribozyme transfected cells as compared to control cells upon serum deprivation. This could be one of the reasons for the anti-tumor effect in vivo. The previous studies have shown that $\mathrm{CD}$ plays a dual role in apoptosis. It prevents apoptosis in physiological and pathological conditions such as cancer while it acts as a key positive mediator during induced apoptosis (32). Also, the secreted pCD has been shown to act as an autocrine/paracrine mitogen and thus the unavailability of pCD might lead to altered signal transduction pathways that mitigate cancer cell growth.

In conclusion, the efficacy of the anti-pCD hammerhead ribozyme as a potential gene therapy agent in human breast cancer has been studied. The specific inhibition and secretion of pCD in breast cancer cells by anti-pCD ribozyme not only inhibits invasion and growth but also induces apoptosis of MDA-MB-231 cells under stress. Our findings provide a new insight into targeting the $\mathrm{pCD}$ by hammerhead ribozyme to intervene aggressiveness of breast cancer and an experimental basis for future therapeutic implications.

\section{Acknowledgements}

This study was supported by research grant from National Institute of Health (NIH RO1CA82159-01A2).

\section{References}

1. Rochefort H: Cathepsin D in breast cancer: a tissue marker associated with metastasis. Eur J Cancer 28: 1780-1783, 1992.

2. Leto G, Gebbia N, Rausa L and Tumminello FM: Cathepsin D in the malignant progression of neoplastic diseases (review). Anticancer Res 12: 235-240, 1992.

3. Reid WA, Vallor MJ and Kay J: Immunolocalization of cathepsin D in normal and neoplastic human tissues. J Clin Pathol 39: 1323-1330, 1986.

4. Richo G and Conner GE: Structural requirements of procathepsin D activation and maturation. J Biol Chem 269: 14806-14812, 1994.

5. Puri J and Factorovich Y: Selective inhibition of antigen presentation to cloned $\mathrm{T}$ cells by protease inhibitors. J Immunol 141: 3313-3317, 1988.

6. Diment S, Martin KJ and Stahl PD: Cleavage of parathyroid hormone in macrophage endosomes illustrates a novel pathway for intracellular processing of proteins. J Biol Chem 264: 13403-13406, 1989.

7. Leto G, Tumminello FM, Crescimanno M, Flandina C and Gebbia N: Cathepsin D expression levels in non-gynecological solid tumors: clinical and therapeutic implications. Clin Exp Metastasis 21: 91-106, 2004.

8. Rochefort H and Liaudet-Coopman E: Cathepsin D in cancer metastasis: a protease and a ligand. APMIS 107: 86-95, 1999.

9. Brouillet JP, Dufour F, Lemamy G, Garcia M, Schlup N, Grenier J, Mani JC and Rochefort H: Increased cathepsin D level in the serum of patients with metastatic breast carcinoma detected with a specific pro-cathepsin D immunoassay. Cancer 79: 2132-2136, 1997.

10. Tandon AK, Clark GM, Chamness GC, Chirgwin JM and McGuirre WL: Cathepsin D and prognosis in breast cancer. N Engl J Med 322: 297-302, 1990.

11. Thorpe SM, Rochefort H, Garcia M, Freiss G, Christensen IJ, Khalaf S, Paolucci F, Pau B, Rasmussen BB and Rose C: Association between high concentrations of Mr 52,000 cathepsin $\mathrm{D}$ and poor prognosis in primary human breast cancer. Cancer Res 49: 6008-6014, 1989.

12. Foekens JA, Look MP, Bolt-de Vries J, Meijer-van Gelder ME, van Putten WL and Klijn JG: Cathepsin-D in primary breast cancer: prognostic evaluation involving 2810 patients. Br J Cancer 79: 300-307, 1999.

13. Jarosz DE, Hamer PJ, Tenney DY and Zabrecky JR: Elevated levels of pro-cathepsin $\mathrm{D}$ in the plasma of breast cancer patients. Int J Oncol 6: 859-865, 1995.

14. Garcia M, Dercoq D, Pujol P and Rochefort H: Overexpression of transfected cathepsin D in transformed cells increases their malignant phenotype and metastatic potency. Oncogene 5: 1809-1814, 1990.

15. Vetvicka V, Benes P and Fusek M: Procathepsin D in breast cancer: what do we know? Effects of ribozymes and other inhibitors. Cancer Gene Ther 9: 854-863, 2002.

16. Birikh KR, Heaton PA and Eckstein F: The structure, function and application of the hammerhead ribozyme. Eur J Biochem 245: $1-16,1997$ 
17. James HA and Gibson I: The therapeutic potential of ribozymes. Blood 91: 371-382, 1998.

18. Wiechen K, Zimmer C and Dietel M: Selection of a high activity c-erbB-2 ribozyme using a fusion gene of c-erbB-2 and the enhanced green fluorescent protein. Cancer Gene Ther 5: 45-51, 1998.

19. Lyngso RB, Zuker M and Pedersen CN: Fast evaluation of internal loops in RNA secondary structure prediction. Bioinformatics 15 : 440-445, 1999.

20. Vetvicka V, Vetvickova $J$ and Benes P: Role of enzymatically inactive procathepsin D in lung cancer. Anticancer Res 24: 2739-2743, 2004.

21. Vetvicka V, Vetvickova J and Fusek M: Anti-human procathepsin D activation peptide antibodies inhibit breast cancer development. Breast Cancer Res Treat 57: 261-269, 1999.

22. Couissi D, Dubois V, Remacle C, Sohonne E and Trouet A: Western immunoblotting and enzymatic activity analysis of cathepsin D in human breast cancer cell lines of different invasive potential. Regulation by 173 -estradiol, tamoxifen and ICI 182,780. Clin Exp Metastasis 15: 349-360, 1997.

23. Berchem G, Glondu M, Gleizes M, Brouillet JP, Vignon F, Garcia M and Liaudet-Coopman E: Cathepsin-D affects multiple tumor progression steps in vivo: proliferation, angiogenesis and apoptosis. Oncogene 21: 5951-5955, 2002.

24. Fusek M and Vetvicka V: Mitogenic function of human procathepsin D: the role of the propeptide. Biochem J 303: 775-780, 1994.

25. Vetvicka V, Vetvickova J, Hilgert I, Voburka Z and Fusek M: Analysis of the interaction of procathepsin $\mathrm{D}$ activation peptide with breast cancer cells. Int J Cancer 73: 403-409, 1997.
26. Benes P, Vashishta A, Saraswat-Ohri S, Fusek M, Pospisilova S, Tichy B and Vetvicka V: Effect of procathepsin D activation peptide on gene expression of breast cancer cells. Cancer Lett 239: 46-54, 2006

27. Laurent-Matha V, Maruani-Herrmann S, Prebois C, Beaujouin M, Glondu M, Noel A, Alvarez-Gonzalez ML, Blacher S, Coopman P, Baghdiguian S, Gilles C, Loncarek J, Freiss G, Vignon F and Liaudet-Coopman E: Catalytically inactive human cathepsin D triggers fibroblast invasive growth. J Cell Biol 168: 489-499, 2005.

28. Eckstein F: Searching for the ideal partner. Nat Biotechnol 16: 24, 1998.

29. Scherr M and Rossi JJ: Rapid determination and quantitation of the accessibility to native RNAs by antisense oligodeoxynucleotides in murine cell extracts. Nucleic Acids Res 26: 5079-5085, 1998.

30. Mathieu M, Vignon F, Capony F and Rochefort H: Estradiol down-regulates the Mannose-6-phosphate/Insulin-like growth factor-II receptor gene and induces cathepsin-D in breast cancer cells: a receptor saturation mechanism to increase the secretion of lysosomal proenzymes. Mol Endocrinol 5: 815-822, 1991.

31. Glondu M, Liaudet-Coopman E, Derocq D, Platet N, Rochefort H and Garcia M: Down-regulation of cathepsin-D expression by antisense gene transfer inhibits tumor growth and experimental lung metastasis of human breast cancer cells. Oncogene 21: 5127-5134, 2002

32. Liaudet-Coopman E, Beaujouin M, Derocq D, Garcia M, Glondu M, Laurent-Matha V, Prebois C, Rochefort $\mathrm{H}$ and Vignon F: Cathepsin D: newly discovered functions of a longstanding aspartic protease in cancer and apoptosis. Cancer Lett 237: $167-179,2006$ 